\title{
Treatment of neuroendocrine tumours of the gastrointestinal tract
}

\author{
K. Öberg
}

\section{Introduction}

Neuroendocrine tumours (NE) of the gastrointestinal tract and pancreas constitute about $2 \%$ of all malignant tumours. They include a number of different tumours, derived from cells of the diffuse neuroendocrine cell-system ${ }^{1}$. The largest group of NE tumours are the so called carcinoids, with an incidence of about 2.5/100.0002, which by tradition have been divided into foregut, midgut and hindgut tumours. Endocrine pancreatic tumours has an incidence of 0.4 $0.8 / 100.000$. This old classification is based on the embryonic origin of the different tumours, where the foregut carcinoid primaries has been located in the lung, thymus, gastric mucosa and the midgut carcinoids with primary tumours in the ileum, caecum and proximal colon and the hindgut carcinoids with the primaries in the distal colon and rectum. This old classification is now about to be abandoned, and more tumour-biology-based classification has emerged. The new WHO-classification is now indicating five subtypes ${ }^{3}$.

1. Well-differentiated endocrine tumour

2. Well-differentiated endocrine carcinoma

3. Poorly-differentiated endocrine carcinoma

4. Mixed exocrine and endocrine carcinomas

5. Tumour-like lesions

This classification can be used for all types of NE tumours, not only for carcinoids. A classical midgut carcinoid will be called with the new terminology A well-differentiated endocrine carcinomas of the ileum, whereas a benign insulin producing tumour of the pancreas will be A well-differentiated endocrine tumour of the pancreas. The differentiation between different tumours types is based on histomorphology, tumoursize and presence or absence of local invasion and/or metas-

Dept. of Endocrine Oncology

University Hospital

Uppsala (Sweden) tases. This new classification of NE tumours is a step forward, although the former classification of carcinoid tumours into foregut, midgut and hindgut, remains clinically available and is still used in many clinical studies. It will take some time for the new classification to receive general acceptance.

NE tumours exhibit substantial differences in terms of genotype and phenotype. Foregut carcinoids mainly pulmonary, but also endocrine pancreatic tumours, frequently show losses of $11 \mathrm{q}$, which represent a characteristic genetic alteration in these tumours. Both typical and atypical carcinoids of the lung show loss of heterozygosity at 11 q13, harboring the multiple endocrine neoplasia Type $1(\mathrm{MEN}-1)$ gene. Atypical carcinoids also show loss of heterozygosity at 3p14-p21.3. Recent studies have shown that carcinoid tumours of the lung and the Gl tract may develop via different molecular pathways. Inactivation of one of several tumours suppressor genes on chromosome 18 may be important for the biological behaviour of $\mathrm{Gl}$ tumours. Familiar midgut carcinoids are rare but bronchial carcinoids as well as endocrine pancreatic tumours and gastric carcinoids may be part of a MEN-1 syndrome ${ }^{4,5}$.

Such differences in molecular genetics and tumour biology play a role for the diagnosis and treatment of neuroendocrine gastrointestinal tumours.

\section{Treatment of NE tumours}

\section{Surgery}

The clinical management of metastatic NE tumours requires a multimodal approach including surgery and other means of cytoreductive treatment, radiotherapy and medical treatment. Surgery remains the treatment of choice and is the only approach that can achieve a complete cure in patients with NE tumours. In cases of metastases, surgery has been used to improve hormone-mediated symptoms, quality of life and survival in certain groups of patients, as well as to reduce tumours bulk and prevent further local and systemic effects. Surgical resection of primary tumours as well as lymph nodes and liver involvement can improve survival. In addition, surgery can also be employed after medical treatment to achieve substantial tumour reduction in an attempt to maxi- 


\section{K. Öberg}

TABLE IA

\section{Cytotoxic therapy for carcinoid tumours}

\begin{tabular}{|c|c|c|c|c|}
\hline Drug & Regimen & Number of patients & Overall response (\%) & Median duration (months) \\
\hline \multicolumn{5}{|l|}{ Single agents } \\
\hline Doxorubicin & $60 \mathrm{mg} / \mathrm{m}^{2}$ every $3-4$ weeks & 81 & 21 & 6 \\
\hline 5-Fluorouracil & $500 \mathrm{mg} / \mathrm{m}^{2} /$ day $\times 5$ every 5 weeks & 30 & $17-26$ & 3 \\
\hline Streptozotocin & $500-1500 \mathrm{mg} / \mathrm{m}^{2} /$ day $\times 5$ every $3-5$ weeks & 14 & $0-17$ & 2 \\
\hline Dacarbazine & $250 \mathrm{mg} / \mathrm{m}^{2} /$ day $\times 5$ every $4-5$ weeks & 15 & 13 & 4.5 \\
\hline $\begin{array}{l}\text { Cisplatin } \\
\text { Combinations }\end{array}$ & $45-90 \mathrm{mg} / \mathrm{m}^{2}$ every $3-4$ weeks & 16 & 6 & 4.5 \\
\hline $\begin{array}{l}\text { Streptozotocin } \\
+5 \text {-fluorouracil }\end{array}$ & $\begin{array}{l}500 \mathrm{mg} / \mathrm{m}^{2} / \text { day } \times 5 \text { every } 3-6 \text { weeks } \\
400 \mathrm{mg} / \mathrm{m}^{2} / \text { day } \times 5 \text { every } 3-6 \text { weeks }\end{array}$ & 175 & $7-33$ & $3-7$ \\
\hline $\begin{array}{l}\text { Streptozotocin } \\
+ \text { doxorubicin }\end{array}$ & $\begin{array}{l}1000 \mathrm{mg} / \mathrm{m}^{2} / \text { week } \times 4 \\
25 \mathrm{mg} / \mathrm{m}^{2} / \text { week then every } 2 \text { weeks }\end{array}$ & 10 & 40 & 5 \\
\hline $\begin{array}{l}\text { Streptozotocin } \\
+ \text { cyclophosphamide }\end{array}$ & $\begin{array}{l}500 \mathrm{mg} / \mathrm{m}^{2} / \text { day every } 6 \text { weeks } \\
100 \mathrm{mg} / \mathrm{m}^{2} \text { once every } 3 \text { weeks }\end{array}$ & 24 & 39 & 6.5 \\
\hline $\begin{array}{l}\text { Etoposide } \\
+ \text { cisplatin }\end{array}$ & $\begin{array}{l}130 \mathrm{mg} / \mathrm{m}^{2} / \text { day } \times 3 \\
45 \mathrm{mg} / \mathrm{m}^{2} / \text { day on day } 2 \text { and } 3, \\
\text { repeat cycle every } 4 \text { weeks }\end{array}$ & 13 & 0 & - \\
\hline
\end{tabular}

mize the disease-free interval ${ }^{6,7}$. Surgery and thermal ablation (radiofrequency treatment) are new promising methods for treatment of liver metastases. Significant clinical improvement and reduction in tumour size has been reported ${ }^{8,9}$.

Liver transplantation has been suggested in selected patients without residual extrahepatic manifestations. However, long-term results are not that encouraging at the moment and the liver transplantation should only be reserved for a very few patients, where other means of therapy cannot control the disease?

\section{Enbolization/chemoenbolization}

A significant number of patients carry liver metastases at diagnosis, therefore treatment aimed at reducing the tumour bulk in the liver may significantly improve quality of life and survival. Such procedures include embolization of liver metastasis with or without concomitant cytotoxic agents (chemoembolization). Objective symptomatic and hormonal responses are ranging from $65 \%$ to $80 \%$, but the method must be repeated to achieve long-lasting responses.

\section{Radiotherapy}

External radiotherapy has demonstrated limited value. Today this kind of therapy is mainly reserved for treatment of brain metastases and pain related to bone metastases. Tumour-targeted radioactive treatment using radiolabeled somatostatin analogues have been applied during the last years with some encouraging results. The different compounds have been 111 Indium-DTPA-octreotide, 90Y-DOTA-octreotide, 90Y-DOTATOC and MAURITIUS giving about the same results with symptomatic improvement in $40 \%$ of the patients, biochemical responses in $24 \%$ to $30 \%$ and significant tumour reduction in a small number, $5 \%$ to $10 \%$. In order to overcome the limitation of administrating doses of radiotherapy to non octreotide avid lesions and the lack of uptake due to tumour heterogeneity in addition to Ytrium 90 several other
TABLE IB

\section{Cytotoxic Therapy - Endocrine pancreatic tumours}

\begin{tabular}{lccc}
\hline Regimen & No of patients & $\begin{array}{c}\text { Over all } \\
\text { response } \\
\text { rate (\%) }\end{array}$ & $\begin{array}{c}\text { Median } \\
\text { duration }\end{array}$ \\
\hline $\begin{array}{l}\text { Streptozotocin } \\
\text { Streptozotocin } \\
+5 \text {-FU }\end{array}$ & 52 & 42 & NA \\
$\begin{array}{c}\text { Streptozotocin } \\
+ \text { Doxorubicin }\end{array}$ & 106 & $31-63$ & $14-23 \mathrm{mo}$ \\
$\begin{array}{c}\text { Streptozotocin } \\
+ \text { Doxorubicin } \\
+5 \text {-FU }\end{array}$ & 11 & 69 & $18 \mathrm{mo}$ \\
\hline
\end{tabular}

isotopes such as Lutetium 177 and Rhenium-186 are being considered. 177Lu-DOTA-octreotate shows high tumours uptake with a very good ratio of tumour to kidney uptake and is suggested to be an ideal compound for radionuclear treatment. Radiotherapy with this compound has recently been administered to 80 patients with a variety of progressive NE tumours and $49 \%$ showed partial remission ${ }^{10,11}$.

\section{Medical treatment}

Medical treatment of NE tumours includes treatment with both chemotherapy and biological agents, such as somatostatin analogues and interferon-alfa.

\section{Chemotherapy (Table la, Ib)}

Chemotherapy has been considered the gold standard for treatment of most NE tumours, however, it is usually reported for only a limited number of patients and with variable crite- 
TABLE ॥

Neuroendocrine tumours: somatostatin analogue therapy (summary of several trials)

\begin{tabular}{|c|c|c|c|}
\hline Response & $\begin{array}{c}\text { Standard dose } \\
(100-1500 \mu \mathrm{g} / \text { day })\end{array}$ & $\begin{array}{c}\text { High dose } \\
\text { (>3000 } \mu \mathrm{g} / \text { day) }\end{array}$ & $\begin{array}{c}\text { Slow release } \\
(20-30 \mathrm{mg} / \text { day every } 2-4 \text { weeks })\end{array}$ \\
\hline $\begin{array}{l}\text { Symptomatic (\%) } \\
\text { Biochemical (\%) }\end{array}$ & $64(146 / 228)$ & $42(11 / 26)$ & $63(76 / 119)$ \\
\hline -complete response & $11(6 / 54)$ & $3(1 / 33)$ & $3(3 / 119)$ \\
\hline -partial response & $55(116 / 211)$ & $72(24 / 83)$ & $64(76 / 119)$ \\
\hline -stable disease & $34(72 / 211)$ & $21(7 / 33)$ & $18(21 / 119)$ \\
\hline -progressive disease & $11(23 / 211)$ & $3(1 / 33)$ & $15(19 / 119)$ \\
\hline Tumour (\%) & & & \\
\hline -complete response & - & $2(1 / 53)$ & - \\
\hline -partial response & $5(7 / 131)$ & $11(6 / 53)$ & $3(4 / 119)$ \\
\hline -stable disease & $38(50 / 131)$ & $47(25 / 53)$ & $79(94 / 119)$ \\
\hline -progressive disease & $56(74 / 131)$ & $39(21 / 51)$ & $18(21 / 119)$ \\
\hline
\end{tabular}

TABLE III

Therapy with interferon- $\alpha$ in patients with midgut carcinoids

\begin{tabular}{|c|c|c|c|}
\hline Number of patients & Biochemical response (\%) & Subjective response (\%) & Tumour value response (\%) \\
\hline \multirow[t]{2}{*}{$29 \S$} & PR $53(13 / 25)$ & $72(32 / 29)$ & PR 10 (3/29) \\
\hline & SD $36(9 / 25)$ & & SD $86(25 / 29)$ \\
\hline $27 \S \S$ & PR $39(9 / 23)$ & 65 & PR $20(4 / 20)$ \\
\hline \multirow[t]{2}{*}{16} & PR $16(1 / 6)$ & & PR $0(0 / 16)$ \\
\hline & SD $50(3 / 6)$ & $80(4 / 5)$ & SD $66(10 / 15)$ \\
\hline 14 & PR $44(4 / 9)$ & 55 & PR $0(0 / 16)$ \\
\hline \multirow[t]{2}{*}{13} & PR $8(1 / 13)$ & & PR $8(1 / 13)$ \\
\hline & SD $31(4 / 13)$ & 50 & SD $77(10 / 13)$ \\
\hline
\end{tabular}

$\$$ Natural leukocyłe interferon- $\alpha, 6 \mathrm{MU}$ subcutaneously $\times 8$ weeks

$\S \S$ High-dose interferon- $\alpha, 2 a 24 \mathrm{MU} / \mathrm{m}^{2}$ subcutaneously $\times 8$ weeks

PR: Partial response; SD: Stable disease

ria for assessing antitumour responses. Cytotoxic treatment is predominantly used in patients with tumours that show high proliferative capacity and large tumour burden; a proliferation index analyzed by the antibody Ki67 should be above $10 \%$ to $15 \%$. Classical midgut carcinoids with low proliferating capacity (Ki67) usually <2\%) have not benefited from regular cytotoxic treatment. The most common chemotherapy in endocrine pancreatic tumour is a combination of Streptozotocin plus 5-fluorouracil or doxorubicin. Reported objective response-rates has been between $40 \%$ and $70 \%$, whereas in classical midgut carcinoids the same combination has only generated responses of $<10 \%$ with short duration. For anaplastic tumours and high proliferative capacity (Ki67 above $15 \%$ ) combination with cisplatinum and etoposide has been particularly useful with a response-rate up to $67 \%$ with a tendency to more prolonged survival ${ }^{12}$.

\section{Somatostatin analogues (Table II)}

The rationale for the clinical use of somatostatin analogues is based on the identification of high-affinity somatos- tatin receptors in $80 \%$ to $90 \%$ of NE tumours. Regular octreotide at a subcutaneous daily dose of $200-450$ g is associated with a median $60 \%$ symptomatic, $70 \%$ biochemical and $8 \%$ tumour response. A limited number of patients have been reported with partial tumour regression during treatment with somatostatin analogues, and very few cases have shown complete tumour regression. However, a high number of patients reached disease stabilization. Today slow-release formulations of octreotide Sandostatin $\operatorname{LAR}^{\circledR}$ and Somatuline Autoge ${ }^{\circledR}$ have been effective with a monthly dosage of 20-30 mg Sandostatin LAR ${ }^{\circledR}$ or 60-120 mg Somatuline Autoge ${ }^{\circledR}$. SOM230 is a new somatostatin analogue which has a prolonged half-live, (approximately 24h) and exerts a more potent inhibitory effect than currently available compounds as it binds with much higher affinity to somatostatin receptors 1, 2, 3 and 5 . The introduction of SOM230 into clinical practice will address a long-standing question as to whether somatostatin receptor subtypes 1 and 3 , which mediate antitumour effects (cell cycle inhibition and induction of apoptosis) will be clinically beneficial in NE tumours ${ }^{13,14}$. 


\section{K. Öberg}

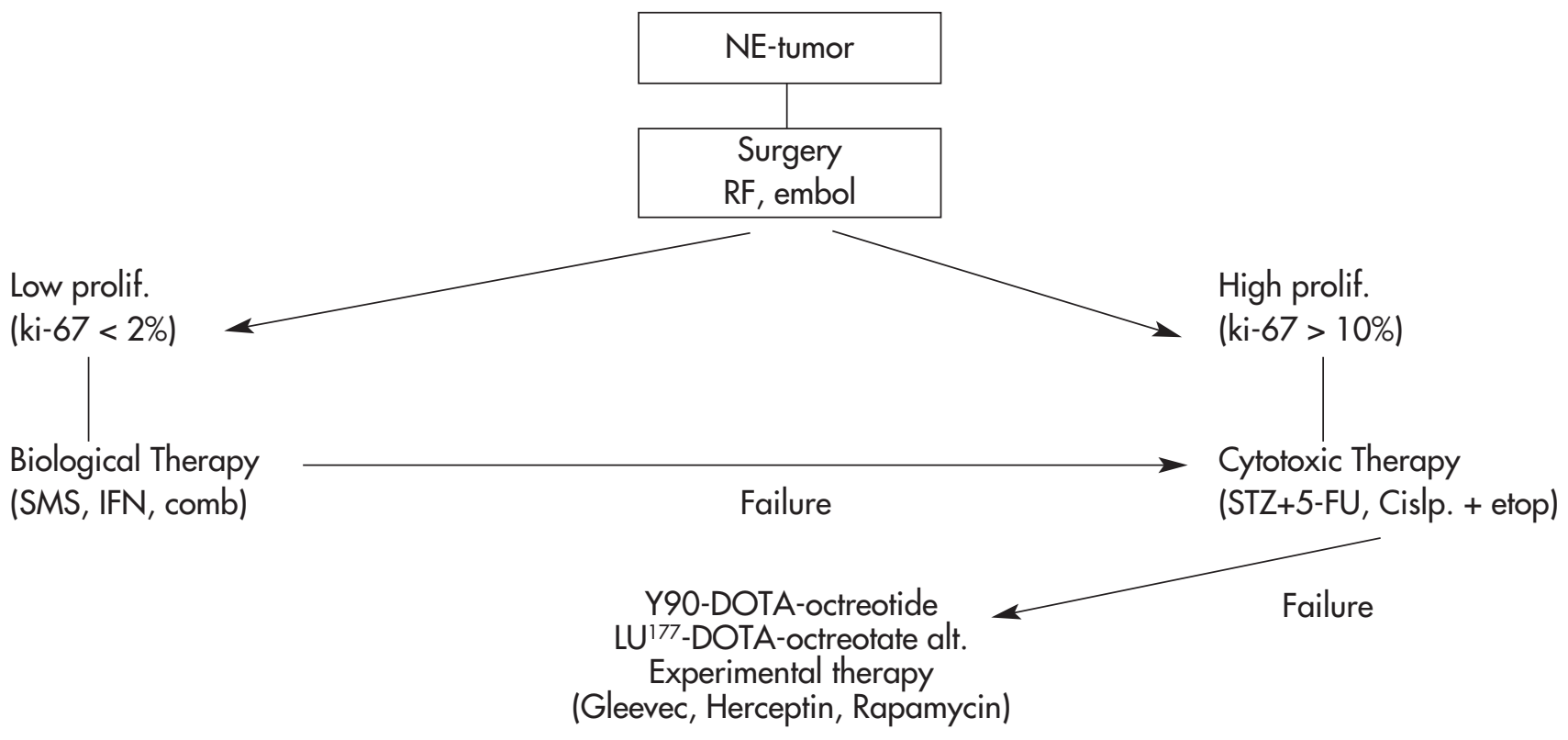

Fig. 1. Algorithm for the therapy of Neuroendocrine Tumours.

\section{Interferons (Table III)}

Interferons are compounds known to exert a combination of effects directed to several groups of tumours and are considered as biological response modifiers as they interact with other soluble or cell-associated regulatory factors. The recommended dose of interferon-alfa is 3-9 MU every other day, subcutaneously or slow release formulation pegylated interferon alfa 80-100 $\mu \mathrm{g}$ once a week, subcutaneously. Data derived from several studies of carcinoid tumours have reported a median symptomatic and biochemical response rate of $40 \%$ to $70 \%$ and biochemical response in $40 \%$ to $60 \%$ and a significant tumour reduction in 10\% to $12 \%$ of patients. Disease stabilization is noted in a further $35 \%$ of the patients. Flu-like symptoms are almost universal with interferon treatment but are usually short lasting. Chronic fatigue and mild depression may develop in approximately $50 \%$ of patients. Autoimmune reactions appear in approximately $15 \%$ of patients 15,16 .

\section{Combination therapy with IFN $\alpha$ and somatostatin analogue}

Patients for whom mono-therapy with interferon alone or octreotide alone could not control the disease have received the combination. Both hormone levels and clinical symptoms were controlled in $40 \%-70 \%$ of the patients but also tumour growth in one third ${ }^{16}$.

The therapy of Neuroendocrine Tumours is summarized in an algorithm (Fig. 1).

\section{New compounds}

Inhibition of the intracellular signal transduction from tyrosine kinase receptors may be new targets in the treatment of NE tumours. Many NE tumours express platelet-derived growth factor alfa- and beta-receptor subtypes and ligands and also
EGF-receptor. Another interesting new compound is Rapamycin, which may block signal transduction through the m-TOR pathway. Clinical trials with this compound as a single agent or in combination with cytotoxic agents are planned. Over the next five years the precise role of tumour-targeted radioactive treatment with somatostatin analogue-based compounds will be defined. New somatostatin analogues, such as SOM230 and somatostatin receptor subtype-specific analogues will also be developed. The tumour biology for different subtypes of NE tumours will be defined and thus new treatments including tyrosine kinase inhibitors, antiangiogenic compounds as well as combinations of these, will be applied in clinical trials.

\section{References}

1. Kimura W, Kuroda, A, Morioka, Y. Clinical pathology of endocrine tumors of the pancreas. Dig Dis Sci 1991; 36:933-42.

2. Modlin IM, Lye KD, Kidd M. A 5-decade analysis of 13,715 carcinoid tumors. Cancer 2003; 97:934-59.

3. Solcia E, Kloppel, G, Sobin, LH. Histological Typing of Endocrine Tumours. In: New York USA: Springer 2000; 38-74.

4. Rindi G, Villanacci V, Ubiali A. Biological and molecular aspects of gastroenteropancreatic neuroendocrine tumors. Digestion 2000; 62 Suppl 1:19-26.

5. Oberg K. Carcinoid tumors: molecular genetics, tumor biology, and update of diagnosis and treatment. Curr Opin Oncol 2002; 14:38-45.

6. Thompson GB, van Heerden JA, Grant CS et al. Islet cell carcinomas of the pancreas: a twenty-year experience. Surgery 1988; 104:1011-7.

7. Hellman $P$, Lundstrom $T$, Ohrvall $U$ et al. Effect of surgery on the outcome of midgut carcinoid disease with lymph node and liver metastases. World J Surg 2002; 26:991-7. 
8. Ruszniewski P, Malka D. Hepatic arterial chemoembolization in the management of advanced digestive endocrine tumors. Digestion 2000; 62 Suppl 1:79-83.

9. Le Treut YP, Delpero JR, Dousset B et al. Results of liver transplantation in the treatment of metastatic neuroendocrine tumors. A 31-case French multicentric report. Ann Surg 1997; 225:355-64.

10. De Jong M BW, Bernard HF et al. Response to radionuclide therapy using $90 \mathrm{Y}$ and $111 \mathrm{ln}$-labeled somatostatin analogs in dependent on tumor size. J Nucl Med 2000; 41:147.

11. Kwekkeboom DJ, Bakker WH, Kooij PP et al. (177Lu-DOTAOTyr3)octreotate: comparison with (1 11 ln-DTPAo)octreotide in patients. Eur J Nucl Med 2001; 28: 1319-25.

12. Oberg K. Chemotherapy and biotherapy in the treatment of neuroendocrine tumours. Ann Oncol 2001; 12 Suppl 2:S111-4.

13. Eriksson B, Oberg K. Summing up 15 years of somatostatin analog therapy in neuroendocrine tumors: future outlook. Ann Oncol 1999; 10 Suppl 2:S31-8.

14. Weckbecker G, Briner U, Lewis I, Bruns C. SOM230: a new somatostatin peptidomimetic with potent inhibitory effects on the growth hormone/insulin-like growth factor-l axis in rats, primates, and dogs. Endocrinology 2002; 143:4123-30.

15. Oberg K, Eriksson B. The role of interferons in the management of carcinoid tumors. Acta Oncol 1991; 30: 519-22.

16. Fjallskog ML, Sundin A, Westlin JE et al. Treatment of malignant endocrine pancreatic fumors with a combination of alpha-interferon and somatostatin analogs. Med Oncol 2002; 19:35-42. 